\title{
ARTICLE
}

\section{Activation analyses of air by deuteron beam at 5-9 MeV}

\author{
Hiroki Takahashi ${ }^{\mathrm{a}^{*},}$ Sunao Maebara ${ }^{\mathrm{b}}$, Hironao Sakaki ${ }^{\mathrm{c}}$, Masahiro Ichikawa ${ }^{\mathrm{a}}$, \\ Hiromitsu Suzuki $^{\mathrm{a}}$ and Masayoshi Sugimoto ${ }^{\mathrm{a}}$ \\ ${ }^{a}$ Japan Atomic Energy Agency (JAEA), 2-166 Obuchi-Omotedate, Rokkasho-mura, Kamikita-gun, Aomori-ken, 039-3212, Japan; \\ ${ }^{b} J A E A$, 2-4 Shirakata, Tokai-mura, Naka-gun, Ibaraki-ken, 319-1195, Japan; ' JAEA, 8-1-7 Umemidai, Kizu-city, Kyoto-fu, \\ 619-0215, Japan
}

\begin{abstract}
A construction of accelerator-based neutron irradiation facility is required to develop materials for a demonstration fusion reactor. To obtain a $14 \mathrm{MeV}$ neutron energy using the neutron-generating D-Li stripping reaction, an injection into liquid lithium flow by a $40 \mathrm{MeV}$ deuteron beam is employed in IFMIF design concept. In the acceleration of deuteron beam, the activation due to the beam loss is a critical issue. The activation analyses for the air in an accelerator vault are performed by PHITS code and DCHAIN code in the first step, using the experimental data for deuteron induced thick target neutron yield at $5 \mathrm{MeV}$ and $9 \mathrm{MeV}$ as source term and a simple model of the $1 \mathrm{~m}$-long beam duct. For the $9 \mathrm{MeV}-1 \mu \mathrm{A}$ beam loss, ${ }^{41} \mathrm{Ar}$ and ${ }^{16} \mathrm{~N}$ are dominant for isotope production, it is evaluated to be $2.95 \times 10^{-1}$ and $1.04 \times 10^{-1} \mathrm{~Bq} / \mathrm{cm}^{3}$, respectively. It is found that the amount of ${ }^{41} \mathrm{Ar}$ reaches the permissible air concentration of $0.1 \mathrm{~Bq} / \mathrm{cm}^{3}$ after an 8-hour $\mathrm{CW}$ operation.
\end{abstract}

Keywords: accelerator; deuteron; isotope production; activation analysis; PHITS code; DCHAIN code

\section{Introduction}

International Fusion Materials Irradiation Facility (IFMIF) is an accelerator-driven neutron irradiation facility to develop materials for DEMO, a demonstration fusion reactor next to ITER [1]. In IFMIF design, an accelerator-based neutron irradiation facility is needed. And, to obtain the simulated neutron spectra produced by $D-T$ reaction and the neutron flux of $10^{18} \mathrm{n} / \mathrm{m}^{2} / \mathrm{s}$ or more, the neutron-generating $\mathrm{D}-\mathrm{Li}$ stripping reaction is adopted and a $40 \mathrm{MeV}$ deuteron beam with a current of $250 \mathrm{~mA}$ has to be injected into liquid lithium flow.

On the accelerator system for deuteron beam, activation for the air and accelerator components due to deuteron beam loss is a critical issue. For the air activation, ${ }^{14} \mathrm{~N}(\mathrm{n}, 2 \mathrm{n}){ }^{13} \mathrm{~N}, \quad{ }^{16} \mathrm{O}(\mathrm{n}, 2 \mathrm{n}){ }^{15} \mathrm{O}, \quad{ }^{16} \mathrm{O}(\mathrm{n}, \mathrm{p}){ }^{16} \mathrm{~N}$, ${ }^{40} \operatorname{Ar}(n, \alpha){ }^{37} \mathrm{~S}$ and ${ }^{40} \operatorname{Ar}(\mathrm{n}, \gamma){ }^{41} \mathrm{Ar}$ have to be evaluated at least. In the first step for order estimation, these isotope productions are calculated by PHITS code and DCHAIN code using the experimental data for source term.

\section{Background}

There is literature on the experimental data of $\mathrm{Cu}+\mathrm{d}$ thick target neutron yield (TTNY) in the range of deuteron energy for 4 and $10 \mathrm{MeV}$, but there is no experimental data for 5-9 MeV. Therefore, we measured

*Corresponding author. Email: takahashi.hiroki@jaea.go.jp thick target neutron yields at 5 and $9 \mathrm{MeV}$ in collaboration with Kyushu University [2][3].

A $0.2 \mathrm{~mm}$ thick copper was used as a target, and the average beam current of $10 \mathrm{nA}$ was injected into the target. For the neutron distribution in all directions, the measured energy spectra at angles, $0^{\circ}, 15^{\circ}, 30^{\circ}, 45^{\circ}, 60^{\circ}$, $75^{\circ}, 90^{\circ}, 120^{\circ}$ and $140^{\circ}$ are used for a source term, and

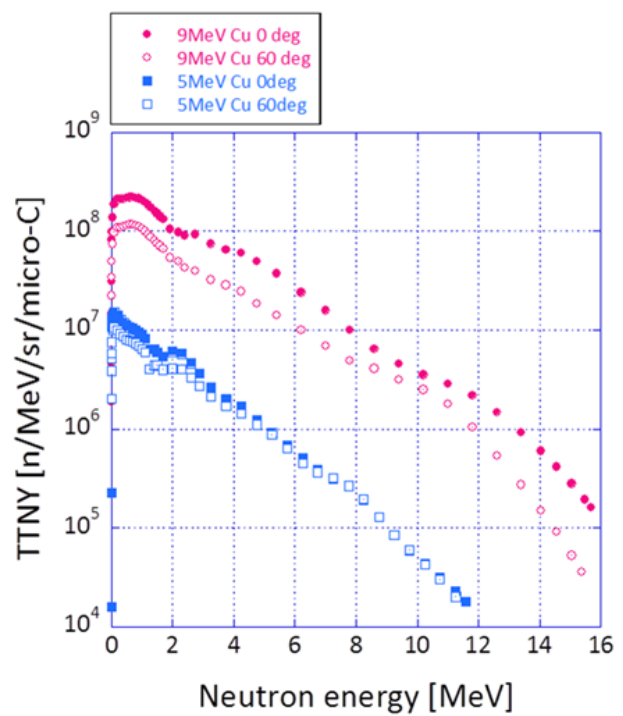

Figure 1. Neutron energy distributions produced at the angles of $0^{\circ}, 60^{\circ}$ with $9 \mathrm{MeV}$ and $5 \mathrm{MeV}$ deuteron beam bombardment on a copper target. 
this source term is set for a surface source in the inside of $1 \mathrm{~m}$-long beam duct. For example, the neutron energy distributions at angles of $0^{\circ}$ and $60^{\circ}$ for $9 \mathrm{MeV}$ and $5 \mathrm{MeV}$ deuteron beams are shown in Figure 1.

\section{Analysis}

\subsection{Model}

A simplified cylindrical model for beam duct and an outer cylindrical air region around the beam duct with a common center axis are used in these analyses. The model parameters are shown in Figure 2. A beam duct is $5 \mathrm{~cm}$ internal radius, $0.5 \mathrm{~cm}$ thickness and $1 \mathrm{~m}$-long. Air area is $305.5 \mathrm{~cm}$ radius which means the thickness of air area is $300 \mathrm{~cm}$. This radius ( $\mathrm{r} 2$ in Figure 2) is defined with the assumption that the required minimum size of accelerator vault will be about $30 \mathrm{~m}^{2}$ (about 6 m-width $\times 5$ m-high).

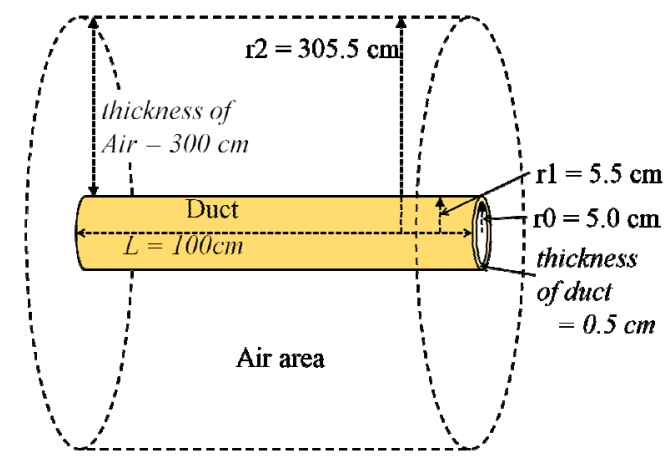

Figure 2. Analysis Model.

\subsection{Analysis condition}

The beam loss is distributed uniformly over the inside wall area of beam duct, and the total beam loss of $1 \mu \mathrm{A}$ for the beam duct of $1 \mathrm{~m}$-long $(1 \mu \mathrm{A} / \mathrm{m})$ is assumed. During an operation time of 8 -hour $\mathrm{CW}$, the amount of each isotope productions is analyzed. Table 1 shows the material components of the air.

Table 1. Mass ratio of constituent gas in air.

\begin{tabular}{cc}
\hline Components & Mass ratio \\
\hline $\mathrm{N}_{2}$ & 0.7551 \\
\hline $\mathrm{O}_{2}$ & 0.2301 \\
\hline $\mathrm{Ar}$ & 0.01286 \\
\hline $\mathrm{CO}_{2}$ & 0.000314 \\
\hline
\end{tabular}

\subsection{Calculation of neutron spectra}

In the realistic system of accelerator, neutron flux is produced not only a beam duct of the limited area ("Air area" in Figure 1) but also the other ducts where exist upstream and downstream. Therefore, $10 \mathrm{~m}$-long cylindrical air area which is ten times longer than the beam duct length define to avoid the underestimate of neutron flux in "Air area". Neutrons generated from 1 $\mathrm{m}$-long beam duct located in the center of the $10 \mathrm{~m}$-long cylindrical air area is considered as neutrons in "Air area".

With the assumption that deuteron beam operation of each $9 \mathrm{MeV}$ and $5 \mathrm{MeV}$ cases, the neutron spectra of "Air area" around a beam duct are calculated by PHITS code, which uses the JENDL 4.0 for nuclear cross-section library. These parameters for calculation of neutron spectra are shown in Table 2.

Table 2. Parameters for the calculation of neutron spectra.

\begin{tabular}{|c|c|c|}
\hline \multirow{5}{*}{ Beam Duct } & Length (L) & $100 \mathrm{~cm}$ \\
\hline & Internal radius $(\mathrm{r} 0)$ & $5.0 \mathrm{~cm}$ \\
\hline & External radius (r1) & $5.5 \mathrm{~cm}$ \\
\hline & Thickness of duct & $0.5 \mathrm{~cm}$ \\
\hline & Materials & $\begin{array}{c}\text { copper, } \\
\text { Stainless } \\
\text { Steel }^{(*)}\end{array}$ \\
\hline \multirow{4}{*}{ Air } & $\begin{array}{l}\text { Length for calculation of } \\
\text { neutron spectra } \\
\text { (same as Figure 2.) }\end{array}$ & $100 \mathrm{~cm}$ \\
\hline & $\begin{array}{l}\text { Length for calculation of } \\
\text { neutrons (first calculation) }\end{array}$ & $1000 \mathrm{~cm}$ \\
\hline & Radius (r2) & $305.5 \mathrm{~cm}$ \\
\hline & Thickness of air area & $300 \mathrm{~cm}$ \\
\hline
\end{tabular}

*) Copper data are used as a neutron source term.

In Figure 3, the neutron flux from beam duct due to deuteron beam loss of $9 \mathrm{MeV}-1 \mu \mathrm{A}$ is indicated. The air around the beam duct is irradiated by neutron flux from $10^{-7}$ to $10^{-4}$ order $\left[1 / \mathrm{cm}^{2} /\right.$ source-particle].

Finally, the radioactivity of "Air area" after an 8-hour CW operation is calculated by DCHAIN using the neutron spectra for under $20 \mathrm{MeV}$ which are results by PHITS code.

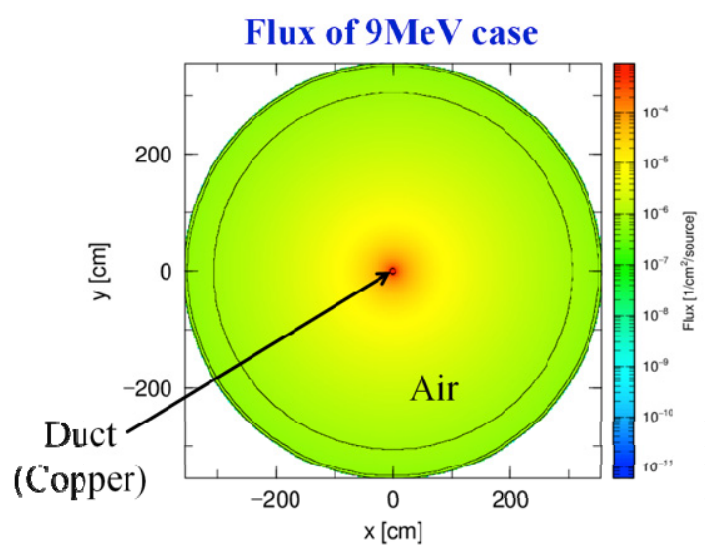

Figure 3. Neutron flux of $9 \mathrm{MeV}$ case.

\subsection{Results}

The calculation results for deuteron beam loss of 9 MeV-1 $\mu \mathrm{A}$ and $5 \mathrm{MeV}-1 \mu \mathrm{A}$ case are shown in Table 3. The value in table shows the radioactivity after an 8-hour CW operation. And, the time-decay of radioisotopes for $9 \mathrm{MeV}$ case is shown in Figure 4.

It is found that the isotope productions of the two cases of the beam ducts of copper $(\mathrm{Cu})$ and stainless steel (SS) are almost same.

In the $9 \mathrm{MeV}-1 \mu \mathrm{A}$ beam loss case, ${ }^{41} \mathrm{Ar},{ }^{16} \mathrm{~N},{ }^{13} \mathrm{~N}$ and 
${ }^{37} \mathrm{~S}$ are dominant after 8-hour $\mathrm{CW}$ beam operation, and the results of their concentrations are $2.95 \times 10^{-1}, 1.04 \times$ $10^{-1}, 1.48 \times 10^{-2}$ and $4.80 \times 10^{-3} \mathrm{~Bq} / \mathrm{cm}^{3}$, respectively. The total radioisotope production is $4.23 \times 10^{-1} \mathrm{~Bq} / \mathrm{cm}^{3}$, and the ${ }^{41} \mathrm{Ar}$ occupies $70 \%$ of the total production. This total production of $4.23 \times 10^{-1} \mathrm{~Bq} / \mathrm{cm}^{3}$ exceeds the permissible air concentration in a radiation controlled area (for example, $0.1 \mathrm{~Bq} / \mathrm{cm}^{3}$ for ${ }^{41} \mathrm{Ar}$ ).

In the beam loss of $5 \mathrm{MeV}-1 \mu \mathrm{A}$, it is found that only ${ }^{41} \mathrm{Ar}$ is dominant and the amount of ${ }^{16} \mathrm{~N},{ }^{13} \mathrm{~N}$ and ${ }^{37} \mathrm{~S}$ can be neglected. Because ${ }^{16} \mathrm{~N},{ }^{13} \mathrm{~N}$ and ${ }^{37} \mathrm{~S}$ are produced by $(n, p),(n, 2 n)$ and $(n, \alpha)$ reactions, and it is strongly dependent on neutron energy of more than $5 \mathrm{MeV}$. The ${ }^{41} \mathrm{Ar}$ production is $3.14 \times 10^{-2} \mathrm{~Bq} / \mathrm{cm}^{3}$, and it is about one tenth of the $9 \mathrm{MeV}-1 \mu \mathrm{A}$ case. This difference can be explained by the difference of low energy neutron flux, since ${ }^{41} \mathrm{Ar}$ is produced by $(n, \gamma)$ reaction.

As shown in Figure 4, the decay of ${ }^{16} \mathrm{~N},{ }^{13} \mathrm{~N}$ and ${ }^{37} \mathrm{~S}$ is very fast, since these half-lives are $7.13 \mathrm{sec}, 9.97 \mathrm{~min}$ and $5.05 \mathrm{~min}$, respectively. The half-life of ${ }^{41} \mathrm{Ar}$ is 1.82 hour, and it takes about 3 hours to fall below the permissible air concentration of $0.1 \mathrm{~Bq} / \mathrm{cm}^{3}$ for ${ }^{41} \mathrm{Ar}$.

The reference data is obtained by the result applied the simple model. By using this result, the air activation of the deuteron accelerator of $100 \mathrm{~mA}$ class is studied. In this case, a $10 \mu \mathrm{A}$ beam loss is assumed and the air activation is estimated. The air concentration for ${ }^{41} \mathrm{Ar}$ after the 8-hour $\mathrm{CW}$ operation is to be 10 times higher

Table 3. Isotope production in the air by calculations.

\begin{tabular}{ccccc}
\hline \multirow{2}{*}{ Isotope } & \multicolumn{2}{c}{$9 \mathrm{MeV}$} & \multicolumn{2}{c}{$5 \mathrm{MeV}$} \\
\cline { 2 - 5 } & $\begin{array}{c}\mathrm{Cu} \\
{\left[\mathrm{Bq} / \mathrm{cm}^{3}\right]}\end{array}$ & $\begin{array}{c}\mathrm{SS} \\
{\left[\mathrm{Bq} / \mathrm{cm}^{3}\right]}\end{array}$ & $\begin{array}{c}\mathrm{Cu} \\
{\left[\mathrm{Bq} / \mathrm{cm}^{3}\right]}\end{array}$ & $\begin{array}{c}\mathrm{SS} \\
{\left[\mathrm{Bq} / \mathrm{cm}^{3}\right]}\end{array}$ \\
\hline Total & $4.23 \times 10^{-1}$ & $4.14 \times 10^{-1}$ & $3.18 \times 10^{-2}$ & $3.12 \times 10^{-2}$ \\
\hline${ }^{3} \mathrm{H}$ & $1.32 \times 10^{-4}$ & $1.34 \times 10^{-4}$ & $4.95 \times 10^{-6}$ & $5.07 \times 10^{-6}$ \\
\hline${ }^{12} \mathrm{~B}$ & $2.59 \times 10^{-3}$ & $2.61 \times 10^{-3}$ & $1.98 \times 10^{-5}$ & $1.99 \times 10^{-5}$ \\
\hline${ }^{14} \mathrm{C}$ & $1.63 \times 10^{-5}$ & $1.60 \times 10^{-5}$ & $1.44 \times 10^{-6}$ & $1.43 \times 10^{-6}$ \\
\hline${ }^{15} \mathrm{C}$ & $7.21 \times 10^{-4}$ & $7.27 \times 10^{-4}$ & $4.84 \times 10^{-6}$ & $4.89 \times 10^{-6}$ \\
\hline${ }^{13} \mathrm{~N}$ & $1.48 \times 10^{-2}$ & $1.49 \times 10^{-2}$ & $1.25 \times 10^{-6}$ & $1.25 \times 10^{-6}$ \\
\hline${ }^{16} \mathrm{~N}$ & $1.04 \times 10^{-1}$ & $1.05 \times 10^{-1}$ & $2.77 \times 10^{-4}$ & $2.78 \times 10^{-4}$ \\
\hline${ }^{37} \mathrm{~S}$ & $4.80 \times 10^{-3}$ & $4.85 \times 10^{-3}$ & $1.10 \times 10^{-4}$ & $1.12 \times 10^{-4}$ \\
\hline${ }^{37} \mathrm{Ar}$ & $5.07 \times 10^{-5}$ & $4.89 \times 10^{-5}$ & $5.44 \times 10^{-6}$ & $5.33 \times 10^{-6}$ \\
\hline${ }^{41} \mathrm{Ar}$ & $2.95 \times 10^{-1}$ & $2.85 \times 10^{-1}$ & $3.14 \times 10^{-2}$ & $3.07 \times 10^{-2}$ \\
\hline
\end{tabular}

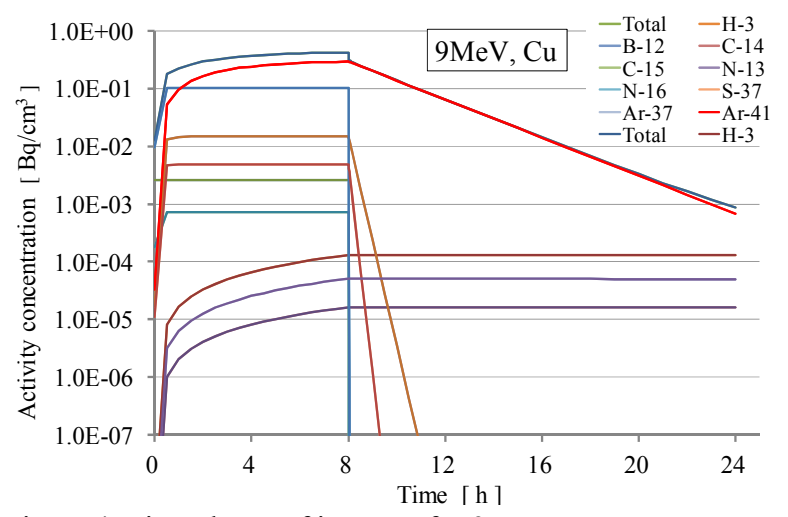

Figure 4. Time-decay of isotopes for $9 \mathrm{MeV}$ case. than the above calculation. And, for the ${ }^{16} \mathrm{~N}$, it is calculated to be $1.04 \times 10^{0} \mathrm{~Bq} / \mathrm{cm}^{3}$ for the $9 \mathrm{MeV}$ case. In order to reduce the ${ }^{41} \mathrm{Ar}$ and ${ }^{16} \mathrm{~N}$, the $(\mathrm{n}, \gamma)$ reaction in the neutron energy range from thermal level to less than $1 \mathrm{MeV}$ and the $(\mathrm{n}, \mathrm{p})$ reaction in the neutron energy of more than $5 \mathrm{MeV}$ have to be suppressed. For this purpose, local shielding using polyethylene or water layer is a good candidate, and an optimized design for the thickness and configuration is indispensable. For the next step, the local shielding designs are in progress.

\section{Conclusion}

An evaluation for the air activation was performed by assuming the deuteron beam loss of $1 \mu \mathrm{A}$ per meter for the beam energy of 5 and $9 \mathrm{MeV}$ by PHITS code and DCHAIN code using the experimental data of deuteron induced thick target neutron yield as a source term.

It is found that the amount of ${ }^{41} \mathrm{Ar}$ exceeds the permissible air concentration $\left(1.0 \times 10^{-1} \mathrm{~Bq} / \mathrm{cm}^{3}\right)$ after an 8-hour $\mathrm{CW}$ operation for the $9 \mathrm{MeV}-1 \mu \mathrm{A}$ beam loss. In consideration of the half-life of ${ }^{41} \mathrm{Ar}, 1.82$ hour, about 3 hours are necessary to fall below $1.0 \times 10^{-1} \mathrm{~Bq} / \mathrm{cm}^{3}$.

On the other hand, at the present accelerator technology, for the accelerated current of $100 \mathrm{~mA}$ class, the $10 \mu \mathrm{A}$ order beam loss is caused at least. Therefore, further study is necessary on the local shielding design, accelerator operation pattern and the air exhaust system to realize the final target, that is, 10 -month $\mathrm{CW}$ operation per every year. Then, for the next step, the local shielding design, accelerator operation pattern and the air exhaust system will be studied.

\section{Acknowledgements}

The authors would like to express their thanks to Dr. Tetsuya Kai of Materials \& Life Science Division, J-PARC in JAEA for continuous support for DCHAIN_SP2001 code usage.

\section{References}

[1] IFMIF-CDA team (edited by M. Martone), IFMIF International Fusion Materials Irradiation Facility Conceptual Design Activity Final Report, ENEA Frascati Report, RT/ERG/FUS/96/11, December 1996.

[2] N. Shigyo, Y. Watanabe, K. Hidaka, Y. Nakamura, D. Moriguchi, M. Kumabe, S. Hirayama, Y. Naitou, C. Motooka, K. Sagara, C. Lan and T. Watanabe, Measurement of deuteron induced thick target neutron yields at $9 \mathrm{MeV}$, Journal of the Korean Physical Society 59(2) (2011), pp. 1725-1728.

[3] K. Hirabayashi, T. Nishizawa, H. Uehara et al., Measurement of Deuteron Induced Thick Target Neutron Yields at $5 \mathrm{MeV}$ and $9 \mathrm{MeV}$, JAEA-Conf 2011-2, pp. 113-118. 